\title{
Habitat selection when killing primary versus alternative prey species supports prey specialization in an apex predator
}

\author{
B. Cristescu ${ }^{1}$, S. Bose ${ }^{2}$, L. M. Elbroch ${ }^{3}$, M. L. Allen ${ }^{2,4}$ \& H. U. Wittmer ${ }^{2}$ \\ ${ }^{1}$ Environmental Studies Department, University of California, Santa Cruz, CA, USA \\ ${ }^{2}$ School of Biological Sciences, Victoria University of Wellington, Wellington, New Zealand \\ ${ }^{3}$ Panthera, New York, NY, USA \\ 4 Illinois Natural History Survey, University of Illinois, Champaign, IL, USA
}

\section{Keywords}

apparent competition; black-tailed deer;

migration; Odocoileus hemionus columbianus; predation; Puma concolor; resource selection function; ungulates.

\section{Correspondence}

Heiko U. Wittmer, School of Biological Sciences, Victoria University of Wellington, PO Box 600 Wellington 6140, New Zealand.

Email: heiko.wittmer@vuw.ac.nz

Editor: Matthew Hayward

Received 11 November 2018; revised 31 May 2019; accepted 28 June 2019

doi:10.1111/jzo.12718

\begin{abstract}
Many predators specialize on one or several prey species that they select from the range of potential prey. Predator specialization on primary versus alternative prey is driven in part by encounter rates with prey and a predator's habitat selection. Although habitat selection changes with behavioural state, this has not been wellrecognized in the resource selection function (RSF) literature to date, often because auxiliary data on the predator's behavioural states (e.g. hunting) are absent. We monitored habitat selection of pumas Puma concolor in a multi-prey system in northern California, where pumas specialized on black-tailed deer Odocoileus hemionus columbianus. We employed multiple RSF analyses on different datasets to test the following three hypotheses: (1) Pumas utilize habitats in proportion to their availability; (2) Pumas select specific habitat features when killing black-tailed deer, their primary prey; (3) Pumas do not select distinct habitats from those identified under hypothesis 1 when killing alternative prey. We found that pumas in our study selected for specific habitats and habitat features in general, but that their selection was more pronounced when killing black-tailed deer. In summer, kill sites of deer were associated with rugged terrain, but gentle slopes and northerly aspects. In winter, pumas killed deer at low elevations, on gentle slopes and on northerly and westerly aspects. Overall, evidence suggested that pumas tracked their primary prey across seasonal migrations, which were short in distance but resulted in pronounced changes in elevation. When killing alternative prey, pumas showed little evidence of habitat selection, suggesting they may kill alternative prey opportunistically. Our results hold implications for how data should be partitioned when modelling baseline habitat selection of predators, hunting habitat selection and predation risk for prey species, as well as for how we model ecological processes such as apparent competition.
\end{abstract}

\section{Introduction}

Many predators specialize on one or several prey species they select from a range of potential prey. When these prey species disproportionally contribute to a predator's numerical response, they are referred to as its primary prey (Holt, 1977). Prey selection for primary versus alternative prey reflects intrinsic predator energetic evolution and predator morphology, as well as extrinsic factors, such as prey availability and vulnerability (Carbone et al., 1999; Hebblewhite, Merrill \& McDonald, 2005; Balme, Hunter \& Slotow, 2007). Predator selection for primary versus alternative prey affects the stability of ecological communities. For example, when a high abundance of primary prey sustains predators at high abundances, they may disproportionately impact alternative prey (i.e. apparent competition; Holt, 1977), initiate Allee effects (McLellan et al., 2010) and drive rare, alternative prey towards extinction (Wittmer et al., 2013).

Prey selection and functional responses are driven by predator encounter rates with prey and a predator's temporal and spatial habitat selection (Holling, 1959; Stephens \& Krebs, 1986; Hopcraft, Sinclair \& Packer, 2005; Fortin et al., 2015). Based on foraging theory, predators should select habitats that increase encounter rates with their primary prey rather than invest in increasing encounters with suboptimal, alternative prey; focusing on primary prey maximizes energy intake and minimizes the costs associated with hunting (Stephens \& Krebs, 1986; Carbone et al., 1999). The behaviours of apex 
predators generally support the habitat selection predictions of optimal foraging theory. For example, grey wolves Canis lupus select habitat that increases encounter rates with their primary prey, and only increase their predation of alternative prey where these prey species co-occur most with primary prey (Treves et al., 2004). Pumas Puma concolor exhibit seasonal prey selection for rare bighorn sheep Ovis canadensis only when migratory bighorn sheep significantly overlap with the puma's primary prey, mule deer Odocoileus hemionus, on winter range (Johnson et al., 2013). African lions Panthera leo in the semi-arid Makgadikgadi ecosystem select for habitat that increases encounter probabilities with their primary prey, but change their habitat selection to increase encounters with alternative prey when their primary prey migrates (Valeix et al., 2012).

Many studies use global positioning system (GPS) locations and resource selection functions (RSFs; Manly et al., 2002) to evaluate animal habitat selection (Sawyer et al., 2007; Dellinger et al., 2013; Ranglack \& du Toit, 2015; Cristescu et al., 2016). However, habitat selection can vary according to behavioural state (Nathan et al., 2008; Cristescu, Stenhouse \& Boyce, 2015; Kusler et al., 2017). Thus, analyses lacking behavioural context may offer generic insights into where animals are likely to occur, but miss the importance of lesser used habitats and their potential fitness benefits (Bose et al., 2018). For carnivores, behavioural states of individuals can be readily identified through interpreting signs found at GPS location clusters of collared individuals (Elbroch, Lowrey \& Wittmer, 2018). Field visitation of GPS clusters is thus widely used by researchers to gain insights into an animal's behaviour and to estimate prey selection and kill rates of large carnivores (Tambling et al., 2010; Pitman, Swanepoel \& Ramsay 2012; Elbroch et al., 2018). These data are also used to quantify and map hunting habitat for carnivores (Elbroch et al., 2013) and its counterpart, risky habitat for prey species (Hopcraft et al., 2005).

Taking advantage of a combination of GPS telemetry and simultaneous information on behaviour, we investigated whether apex predators (pumas) show specialization in habitat selection when killing different types of prey. We focused on pumas in a multiprey system in northern California, and conducted field investigations of aggregated location data to differentiate hunting behaviour from other behaviours, such as resting and scent marking. Black-tailed deer $O$. h. columbianus were the primary prey of this puma population (Allen et al., 2015), and most deer in the area exhibited seasonal, elevational migrations (Bose et al., 2017) that we expected to affect the seasonal habitat selection of pumas. We tested three hypotheses: (1) Pumas will exhibit habitat generalism across seasons, using habitats in proportion to their availability; (2) When hunting primary prey, puma habitat selection will be more refined than that observed in baseline habitat selection; (3) Pumas hunt alternative prey opportunistically and the habitat features associated with alternative prey kill sites will be the same as those for baseline habitat selection (hypothesis 1). To test our hypotheses, we determined seasonal RSF analyses utilizing different subsets of location data: (1) all location data, which we assumed reflected baseline habitat selection across all behavioural states; (2) kill sites of black-tailed deer; and (3) kill sites of alternative prey.

\section{Materials and methods}

\section{Study area}

We conducted our study in and adjacent to the Mendocino National Forest in northern California, USA $\left(39^{\circ} 42^{\prime} \mathrm{N}\right.$, $\left.122^{\circ} 55^{\prime} \mathrm{W}\right)$. The study area encompassed approximately $1000 \mathrm{~km}^{2}$. Elevation in the study area ranged from 400 to $2450 \mathrm{~m}$. Topography and climate are described in detail in Allen et al. (2015). Major vegetation types changed with increasing elevation. At low elevations, plant communities included oak woodlands (Quercus spp., Aesculus californicus, Arctostaphylos spp.), chaparral (Ceanothus spp., Adenostoma fasciculatum) and grasslands (Bromus spp., Avena spp.). Pine (Pinus spp.) forests occurred at mid-elevations, whereas at higher elevations plant communities were dominated by mixedconiferous hardwood forests (Pinus ponderosa, P. iambertiana, Abies concolor, A. magnifica, Pseudotsuga menziesii, Arbutus menziesii, Quercus spp.). Silviculture and cattle grazing were historically the primary land management activities, which resulted in a mosaic of even-aged forest stands and openings dominated by non-native grasses.

Black-tailed deer were functionally the only ungulate prey available to pumas; domestic cattle grazed in the Mendocino National Forest during summer and non-native pigs Sus scrofa occurred at lower elevations but neither were part of the diet of pumas (Allen et al., 2015). A total of 19 alternative prey species, however, contributed to the diet of pumas, including rodents [California ground squirrel (Otospermophilus beecheyi), Douglas squirrel (Tamiasciurus douglasii), golden-mantled ground squirrel (Callospermophilus lateralis), Western grey squirrel (Sciurus griseus), dusky-footed wood rat (Neotoma fuscipes)], lagomorphs [black-tailed jackrabbit (Lepus californicus), brush rabbit (Sylvilagus bachmani)], carnivores [black bear (Ursus americanus), coyote (Canis latrans), fisher (Martes pennanti), grey fox (Urocyon cinereoargenteus), raccoon (Procyon lotor)] and birds [American robin (Turdus migratorius), California quail (Callipepla californica), California towhee (Melozone crissalis), mountain quail (Oreortyx pictus), mourning dove (Zenaida macroura), red-breasted sapsucker (Sphyrapicus ruber), wild turkey (Meleagris gallopavo)] (Allen et al., 2015).

\section{Animal captures and field methods}

Between June 2010 and November 2012, we captured seven pumas (five females, two males) using trained hounds and box traps. One male and one female were classified as subadult (i.e. $<3$ years); all other pumas were considered adults. Capture methods were described in detail in Allen et al. (2015) and approved by the Institutional Animal Care and Use Committee at the University of California, Davis (Protocols 15341 and 16886) and by the Wildlife Investigations Laboratory of the California Department of Fish and Wildlife.

All captured pumas were fitted with ARGOS satellite GPS telemetry collars (Lotek 7000SAW; New Market, Ontario, Canada). We programmed collars to acquire GPS locations at 2-h intervals and downloaded the location data via satellite every 3 days. We displayed location data in ArcGIS 3.2 
(ESRI, Redlands, CA, USA) to identify clusters of GPS points indicating potential prey kill sites. We defined GPS clusters as $\geq 5$ locations (or a minimum of $8 \mathrm{~h}$ between first and last locations) within $150 \mathrm{~m}$ of each other that contained at least one crepuscular or nocturnal location. This is the same definition of clusters used in previous work (e.g. Elbroch \& Wittmer, 2013), except we employed a longer time threshold, as larger clusters are associated with higher probabilities of finding puma kills (Elbroch et al., 2013). Using handheld GPS units (Garmin 60csx), we investigated 598 of the 609 identified clusters to search for possible prey remains on average within one week $(\bar{x}=6.78 \pm 8.18 \mathrm{SD})$ after the puma left the area. We identified prey species found at clusters (i.e. kill sites) through skeletal features and external characteristics (hair, pelage or feathers) and used carcass state and, whenever possible, locations of bite marks to assess whether the prey had been killed or whether pumas had been scavenging.

\section{Kill sites and random sites}

We employed a use-availability RSF design (Manly et al., 2002) to evaluate habitat selection by pumas in three different ways: (1) based on all puma locations, (2) based on 288 identified kill sites of black-tailed deer and (3) based on 64 identified kill sites of alternative prey. We extracted habitat covariates associated with kill sites for the first GPS location of each cluster.

Our procedure follows the framework of within-home range, third order habitat selection analysis (Johnson, 1980) using telemetry locations as use data. To sample available habitats, we first estimated individual $100 \%$ minimum convex polygon home ranges for all seven collared pumas and then performed a sensitivity analysis to inform the choice of the most adequate number of random locations to characterize availability inside puma home ranges (Stabach et al., 2016). Based on sensitivity analysis outputs, we generated 150 random locations per 1 used puma location for habitat selection modelling. The large number of random locations allowed sampling of less common habitat types within the study area (Northrup et al., 2013). Potential bias from 'contamination' or 'false-negatives' (i.e. pixels classified as available that may have been used) due to the large number of random locations was counteracted by sampling at the landscape scale which contained large numbers of available pixels relative to the sample of used pixels. To further reduce false-negatives, we created a buffer with 75-m radius from the centre of each identified prey kill cluster and sampled availability outside these buffers. This buffer radius likely encompassed most kill and feeding sites, the latter being more concealed sites where pumas often drag prey for consumption after making the kill (Allen et al., 2015).

\section{Habitat covariates}

We considered topography (elevation, slope, aspect and ruggedness), vegetation (seven vegetation types), cover (canopy at base height) and edge density as biologically relevant covariates for puma habitat selection analyses (e.g. Elbroch et al., 2013; Robinson et al., 2015; Kusler et al., 2017).

\section{Topography}

We obtained altitude data (elevation; continuous, metre) from the 30-m resolution ASTER (Advanced Spaceborne Thermal Emission and Reflection radiometer) global digital elevation model (GDEM: https://earthexplorer.usgs.gov; accessed 06 February 2015). We derived inclination (slope; continuous, percentage) and aspect (sine [aspect $(E-W)$; continuous, radians] and cosine [aspect $(N-S)$; continuous, radians] transformed) from the ASTER GDEM layer using the Spatial Analyst surface tools in ArcGIS 10.2. We calculated a vector ruggedness measure (ruggedness; continuous, unitless) from the ASTER GDEM in ArcGIS 10.2 following Sappington, Longshore \& Thompson (2007).

\section{Vegetation and edge density}

We acquired vegetation layers including vegetation type and vertical cover [canopy at base height (canopy; continuous, percentage)] from Landscape Fire and Resource Management Planning databases (LandFire; www.landfire.gov; accessed 19 January 2017). To reduce model parameters, we broadly reclassified vegetation types into seven distinct habitat classes (all categorical, unitless): conifer (conifer), hardwood (hardwood), grassland (grassland), riparian (riparian), shrub (shrub), barren and sparse vegetation (open) and developed upland forests, agricultural land and water (other). We used conifer as the reference class for comparison among vegetation types, as it was the most abundant form of vegetation in our study area.

To estimate habitat edge density, we obtained a road layer for our study area from USDA Forest Service maps (https:// www.fs.usda.gov/detail/r5/landmanagement; accessed 25 January 2017) and overlaid it on Google Earth maps. We digitised additional or incomplete tracks and roads within the study area and used this modified layer for the final analysis. We generated a river/stream layer by hydrological modelling of the ASTER DEM layer in ArcGIS 10.2 using the hydrology toolset. We calculated the density of linear feature edges (river/ stream/road edges), defined as the interfaces between these features and any adjacent vegetation type. We also calculated the density of vegetation edges, defined as the interfaces between open (herbaceous vegetation, shrubs and grasslands independent of age as well as regenerating forests $<20$ years old) and closed-canopy (all forest successional classes $\geq 20$ years) vegetation. Calculations were carried out using the Spatial Analyst density tools in ArcGIS 10.2. We combined density of linear feature edges and density of vegetation edges to obtain edge density (edge; continuous, $\mathrm{km} / \mathrm{km}^{2}$ ) information as a predictor variable in our analyses.

\section{Resource selection functions}

We built a set of 15 a-priori candidate models for summer (June-November) and winter (December-May) separately 
(Supporting Information Tables S1-S6). To examine whether site characteristics differed between puma locations, blacktailed deer kill sites, other prey kill sites and available locations, we estimated RSFs for each subset separately using mixed-effects logistic regression of the form;

$$
g(x i j)=\ln \left[\frac{\pi\left(x_{i j}\right)}{1-\pi\left(x_{i j}\right)}\right]=\beta_{0}+\beta_{1} x_{1 i j}+\cdots+\beta_{n} x_{n i j}+\gamma_{0 j}
$$

where $g\left(x_{i j}\right)$ is the model estimated for puma location or kill site location $i$ for puma individual $j ; \pi\left(x_{i j}\right)$ is the conditional mean of $g\left(x_{i j}\right)$ given $x_{i j} ; \beta_{n}$ is the estimated coefficient for covariate $x_{n i j} ; \beta_{0}$ is the mean intercept; and $\gamma_{0 j}$ is the random per-subject intercept, which effectively controls for variation due to unbalanced individual sampling (Gillies et al., 2006).

Before running the RSFs, we tested for multicollinearity among the predictor variables used in each model. Variables with correlation coefficients $\geq|0.6|$ were not used together in any model. We standardized all continuous variables to allow direct comparisons of parameter estimates. We fit generalized linear mixed models (GLMMs) using the library lme4 (Bates et al., 2007) in programme $\mathrm{R}$ ( $\mathrm{R}$ Development Core Team, 2014). We used an information-theoretic approach based on Akaike's Information Criterion with a correction for small sample sizes $\left(\mathrm{AIC}_{\mathrm{c}}\right.$; Burnham \& Anderson, 2002) to identify the best performing models. We retained for interpretation models with $\Delta \mathrm{AIC}_{\mathrm{c}}<4$ and $\Delta \mathrm{AIC}_{\mathrm{c}}<\Delta \mathrm{AIC}_{\mathrm{cNull}}$. However, in cases where competing models with just one additional variable had $\Delta \mathrm{AIC}_{\mathrm{c}}<2$, we maintained for inference only the most parsimonious model, to avoid inclusion of uninformative parameters in our final model set (Arnold, 2010). We estimated relative importance of covariates by ranking independent variables in the final model set based on their summed $\mathrm{AIC}_{\mathrm{c}}$ weights $\left(w \mathrm{AIC}_{\mathrm{c}}\right.$; Symonds \& Moussalli, 2011).

We estimated the fit of models in the final set by calculating the marginal coefficient of determination $\left(R_{\mathrm{GLMM}(\mathrm{m})}^{2}\right)$, which represents the variance explained by fixed factors; and the conditional coefficient of determination $\left(R_{\text {GLMM(c) }}^{2}\right)$, which represents the variance explained by both fixed and random factors (Nakagawa \& Schielzeth, 2013). We calculated the marginal and conditional coefficients of determination in programme $\mathrm{R}$ ( $\mathrm{R}$ Development Core Team, 2014) with the function $\mathrm{r} 2 \mathrm{glmm}$ in the MuMIN package (Barton, 2018). Values of $R_{\text {GLMM(m) }}^{2}$ $<R_{\text {GLMM(c) indicate that random effect inclusion outperforms }}^{2}$ fixed effects alone; whereas $R^{2}{ }_{\mathrm{GLMM}(\mathrm{m})}=R_{\mathrm{GLMM}(\mathrm{c})}^{2}$ suggests that the clustering within subject is either non-existent or too weak to detect.

We assessed predictive ability of our top models with $k$-fold cross-validation (Boyce et al., 2002). We randomly partitioned the data by individual within seasonal models to construct a training set ( $80 \%$ of data) and test set $(20 \%$ of data). We then used model-averaged estimates from our training models to calculate predicted RSF values for the random locations. Subsequently, we ranked the random locations based on predicted values and binned them into 10 equal groups. We quantified the fit using the Spearman rank correlation coefficient based on the frequency of used points in each of 10 equal bins of predicted values (Boyce et al., 2002).

\section{Results}

\section{Puma prey}

Between June 2010 and November 2012, we obtained 19988 GPS relocations from our seven collared pumas $(\bar{x}=2855 \pm 1595 \mathrm{SD}$, range 971-5342) and visited 598 GPS location clusters in the field. Pumas killed black-tailed deer at 288 clusters (mean per puma 41, range 9-65), 203 in summer and 85 in winter. Pumas killed alternative prey at 64 clusters, of which 59 were rodents, lagomorphs and birds and 5 were meso- or large carnivores (Allen et al., 2015). We found more prey clusters of non-deer prey in summer $(n=46)$ than in winter $(n=18)$.

\section{Baseline habitat selection}

Top models that included a random intercept for puma individual had improved fit over fixed effects alone (Supporting Information Tables S1 and S4) and showed that pumas selected for and against a wide variety of habitats (Table 1; Fig. 1).

In summer, pumas selected for rugged terrain, northerly aspects, gentle slopes and areas with high edge density. They also selected shrub and the other habitats category while avoiding grassland (Table 2; Supporting Information Table S7; Supporting Information Fig. S1). Based on the $\mathrm{AIC}_{\mathrm{c}}$ ranking, we retained three models (cumulative $w \mathrm{AIC}_{\mathrm{c}}=1.00$ ) that were complex (range $=10-13$ covariates) (Table 1; Supporting Information Table S1). The top models had excellent power of prediction $\left(r_{\mathrm{s}}=0.95 ; 0.92 ; 0.90\right.$, Fig. 2a).

In winter, pumas selected for low elevations, gentle slopes and northern aspects. They also selected for hardwoods and high edge density, while avoiding open and riparian areas (Table 2; Supporting Information Table S7; Supporting Information Fig. S1). We retained only the full model for winter $\left(w \mathrm{AIC}_{\mathrm{c}}=1.00\right.$; Table 1; Supporting Information Table S4), which had good predictive ability $\left(r_{\mathrm{s}}=0.88\right.$, Fig. $\left.2 \mathrm{c}\right)$.

\section{Habitat selection for black-tailed deer kill sites}

Including a random intercept for puma individual in top models did not improve fit over fixed effects only (Supporting Information Tables S2 and S5). Model outputs showed seasonal variability in habitat selection for deer kills (Table 1 and Fig. 1).

In summer, pumas were more likely to kill black-tailed deer in rugged terrain, on gentle slopes and northerly aspects (Table 2; Supporting Information Table S7; Supporting Information Fig. S1). Overall, only one model containing five covariates was retained for summer $\left(w \mathrm{AIC}_{\mathrm{c}}=0.94\right.$; Table1; Supporting Information Table S2). The predictive power of this model was excellent $\left(r_{\mathrm{s}}=0.92\right.$, Fig. $\left.2 \mathrm{~b}\right)$.

In winter, pumas selected lower elevations, gentle slopes, northerly and westerly aspects when killing deer (Table 2, Supporting Information Table S7, Supporting Information Fig. S1). Three models for selection of deer kill sites were retained for winter (cumulative $w \mathrm{AIC}_{\mathrm{c}}=0.98$; Supporting 


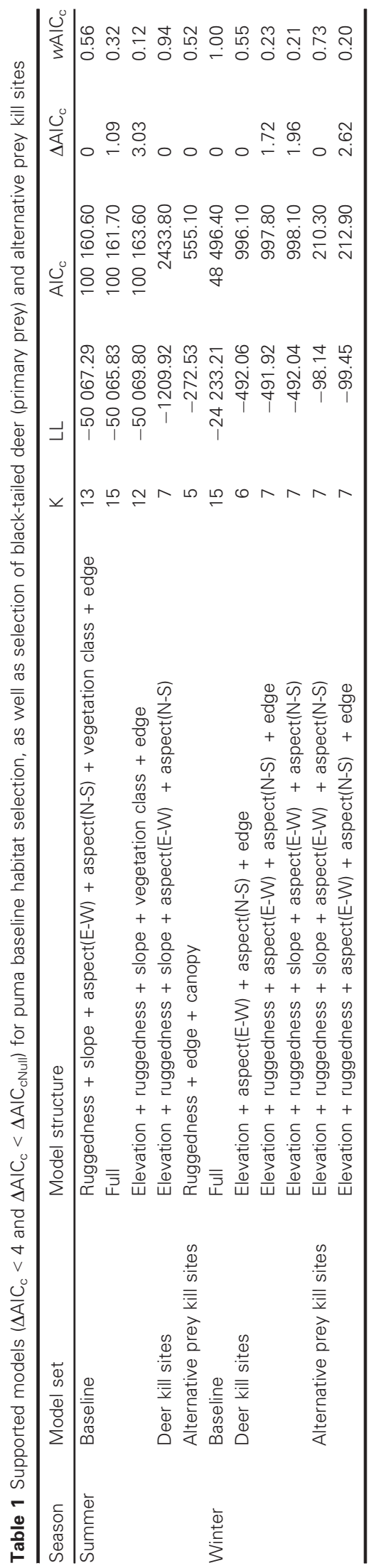

Information Table S5). The models had a relatively small number of covariates (range 4-5) and excellent predictive power $\left(r_{\mathrm{s}}=0.92 ; 0.95 ; 0.94 ;\right.$ Fig. 2d).

\section{Habitat selection for alternative prey kill sites}

The addition of a random intercept for puma individual in the top models did not improve fit compared with fixed effects only (Supporting Information Tables S3 and S6). Pumas showed seasonal variation in habitat selection for non-deer kills (Table 1; Fig. 1).

In summer, high ruggedness was significantly associated with selection of kill sites of non-deer prey species (Table 2, Supporting Information Table S7; Supporting Information Fig. S1). However, there was considerable uncertainty in model selection for kill sites of alternative prey species, as illustrated by the null model having lower $\Delta \mathrm{AIC}_{\mathrm{c}}$ than two models with $\Delta \mathrm{AIC}_{\mathrm{c}}<4$ (Supporting Information Table S3), as well as by $w \mathrm{AIC}_{\mathrm{c}}$ of only 0.52 for the only model with $\Delta \mathrm{AIC}_{\mathrm{c}}<\Delta \mathrm{AIC}_{\mathrm{cNull}}$.

In winter, pumas selected for kill sites of alternative prey at lower elevations (Table 2, Supporting Information Table S7; Supporting Information Fig. S1). This output was derived from two models retained for winter (Supporting Information Table S6), each with five covariates and a cumulative $w \mathrm{AIC}_{\mathrm{c}}$ of 0.93 .

For both seasons, the results of habitat selection for alternative prey kill sites must be interpreted with caution, because small sample sizes precluded estimation of predictive ability. For the same reason, we do not plot seasonal predictive probability surfaces for non-deer kills by pumas.

\section{Discussion}

Pumas in our study selected specific habitats in general, but their selection was more pronounced (as illustrated by fewer predictors in top models) when killing black-tailed deer, their primary prey, than when baseline habitat selection inclusive of all behavioural states was considered. Selection for some habitats was likely associated with increased encounter rates and successful killing of their primary prey, such as in rugged terrain, on gentle slopes and northerly aspects in summer; and at low elevations, on gentle slopes as well as northerly and westerly aspects in winter. Other aspects of selection may have reflected prey vulnerability rather than abundance, such as small prey group sizes in some habitats resulting in decreased overall vigilance; or availability of microhabitat features enabling stalking cover, as has been shown for other large carnivores (Hebblewhite et al., 2005; Balme et al., 2007). Our results also suggested that pumas hunting alternative prey showed limited selection of habitats beyond topographic features including ruggedness in summer and low elevations in winter. This may indicate that pumas kill alternative prey opportunistically, rather than attempt to increase encounter rates with them by selecting for unique habitat features. In contrast, the more refined habitat selection for primary prey as well as their general selection for certain habitats more than 

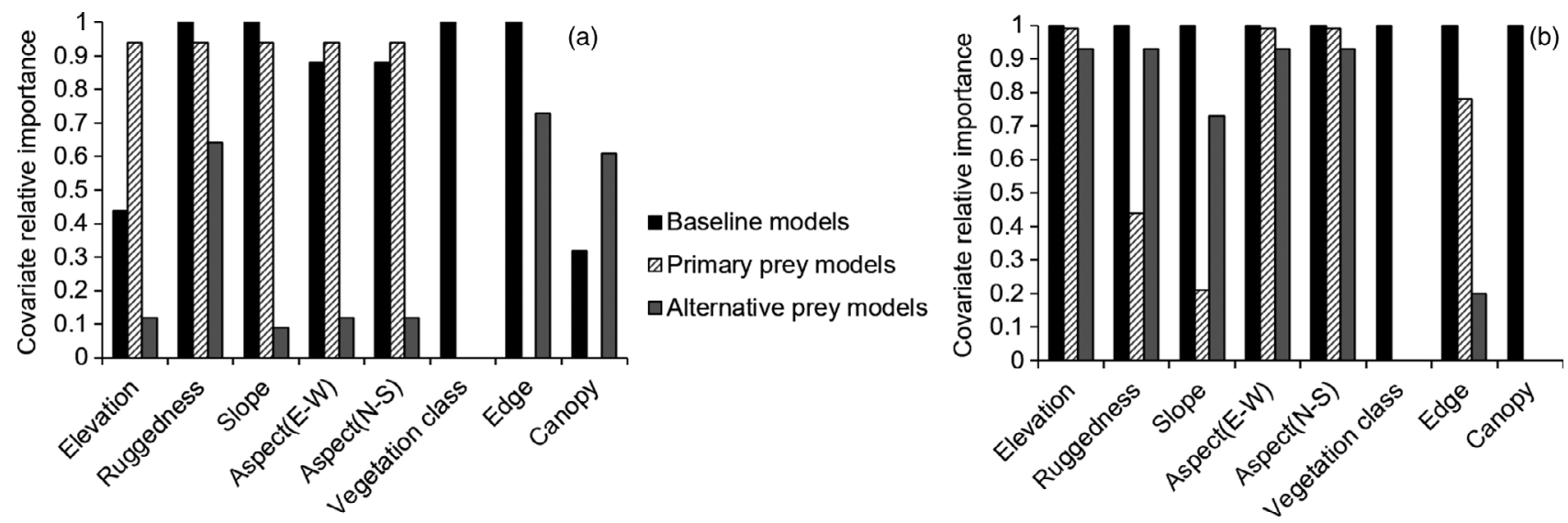

Figure 1 Relative importance of covariates associated with summer (a) and winter (b) puma baseline habitat selection, as well as selection of black-tailed deer and alternative prey kill sites in the Mendocino National Forest, California. Importance values were calculated by summing $\mathrm{AlC}_{\mathrm{C}}$ weights of models that included the respective covariate and which received support $\left(\Delta \mathrm{AICC}<4\right.$ and $\left.\Delta \mathrm{AICC}<\Delta \mathrm{AICC} \mathrm{Null}_{\mathrm{I}}\right)$.

Table 2 Parameter estimates of top models ( $\Delta \mathrm{AICc}<4$ and $\Delta \mathrm{AICc}<\Delta \mathrm{AIC} \mathrm{C}_{\text {Null }}$ ) for puma baseline habitat selection, as well as selection of black-tailed deer and alternative prey kill sites

\begin{tabular}{|c|c|c|c|c|c|c|}
\hline \multirow[b]{2}{*}{ Model covariate } & \multicolumn{3}{|l|}{ Summer } & \multicolumn{3}{|l|}{ Winter } \\
\hline & Baseline & Deer kill sites & Alternative prey kill sites & Baseline & Deer kill sites & Alternative prey kill sites \\
\hline Elevation & ++ & + & & $-*$ & $-^{*}-{ }^{*}-*$ & $-*-^{*}$ \\
\hline Ruggedness & $+^{*}+*+^{*}$ & $+*$ & $+*$ & + & ++ & -- \\
\hline Slope & $-*-^{*}-^{*}$ & $-*$ & & $-*$ & $-*$ & - \\
\hline Aspect(E-W) & -- & + & & + & $+^{*}+{ }^{*}+*$ & -- \\
\hline Aspect(N-S) & ${ }^{*}$ - $^{*}$ & $-*$ & & $-*$ & $-*{ }^{*}-*$ & -- \\
\hline Grassland & $-^{*}-*{ }^{*}$ & & & + & & \\
\hline Hardwood & +++ & & & $+^{*}$ & & \\
\hline Open & +++ & & & $-^{*}$ & & \\
\hline Other & $+*+^{*}+*$ & & & - & & \\
\hline Riparian & +++ & & & $-*$ & & \\
\hline Shrub & $+^{*}+*+^{*}$ & & & + & & \\
\hline Edge & $+^{*}+{ }^{*}+*$ & & + & $+*$ & ++ & - \\
\hline Canopy & - & & - & - & & \\
\hline
\end{tabular}

The direction of the parameter estimate ("+" or "-") is provided. Estimates for which $95 \%$ confidence intervals did not overlap zero have an asterisk.

expected given their availability suggested that puma habitat selection might be more specialized than previously thought (Sunquist \& Sunquist, 2002; Stoner et al., 2013; Warren et al., 2016). Because habitat selection is influenced by behavioural state, empirical data on animal behaviour such as collected in this study, or behavioural state inference from state-space modelling (Patterson et al., 2008) should be used routinely to improve understanding of habitat selection (and hence animal distribution)

Outputs of baseline habitat selection models lead us to reject our first hypothesis that pumas would exhibit habitat generalism across seasons, using habitats proportionally to their availability. For example, pumas selected lower elevations in winter, likely because most black-tailed deer congregated on distinct ranges at lower elevations during winter (Bose et al., 2017). Pumas also selected for and against several habitats throughout the year, including selecting for northerly aspects and edge habitats while avoiding steep slopes throughout the year. Edge habitats in particular have previously been identified as important habitats for pumas and have been linked to hunting (Holmes \& Laundré, 2006). Shrub and hardwood forest habitats were selected in summer and winter, respectively, whereas grasslands and other open habitats as well as riparian areas were avoided seasonally. Black-tailed deer in our study area mostly selected for these same features (Bose et al., 2018), suggesting pumas may be selecting these areas as hunting habitats with abundant primary prey. Individual pumas varied in their habitat selection, but our sample sizes were too small to determine whether puma age or sex explained this variation.

We found support for our second hypothesis, that puma habitat selection when killing their primary prey would deviate 

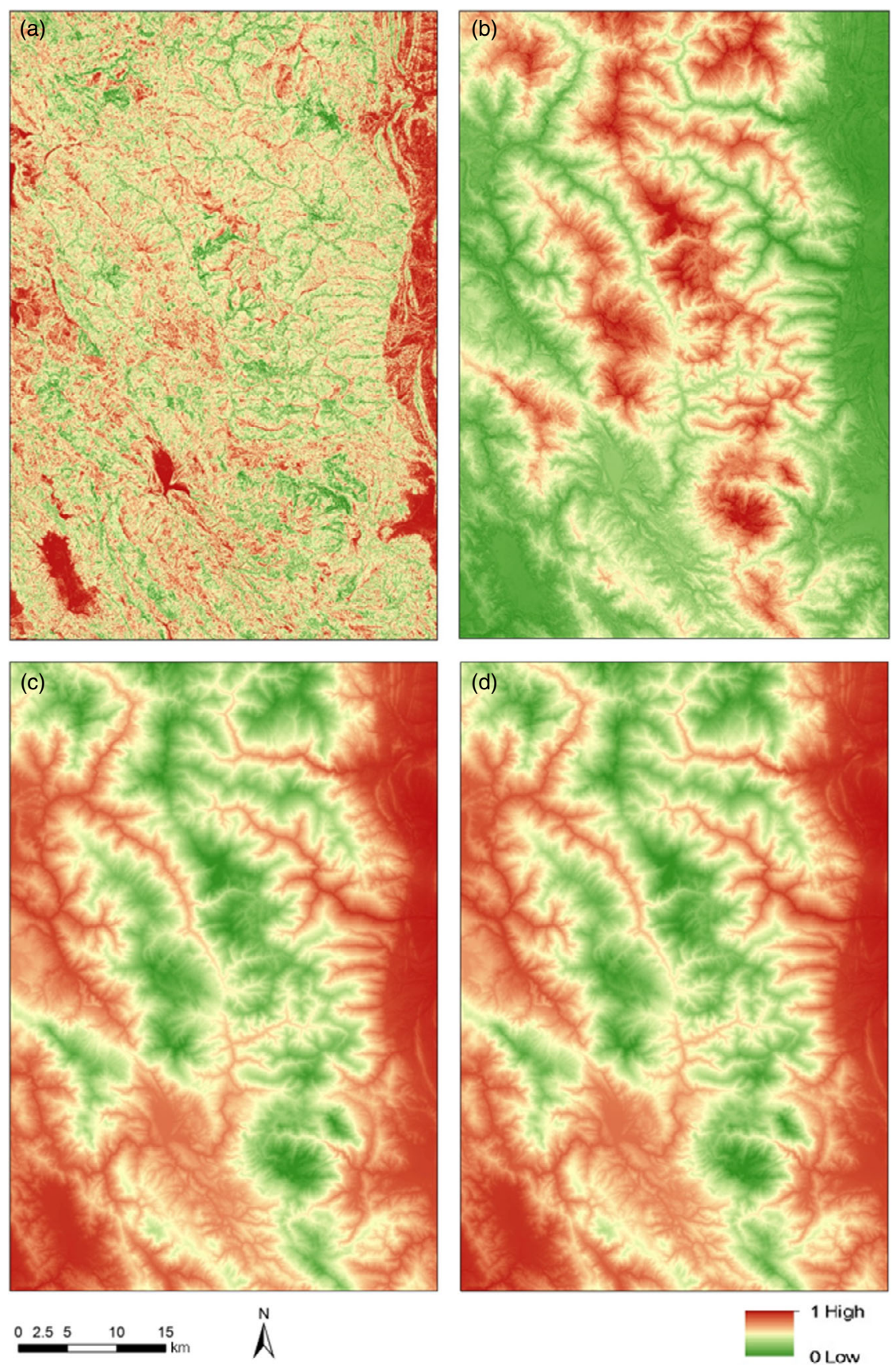

Figure 2 Predicted relative probability of puma habitat suitability in the Mendocino National Forest, California. Separate predictions are presented for puma baseline habitat selection in summer (a); selection of black-tailed deer kill sites in summer (b); baseline habitat selection in winter (c); and selection of black-tailed deer kill sites in winter (d).

from baseline selection reflecting more refined choices. Specifically, pumas were more likely to kill black-tailed deer on gentle slopes and northerly aspects irrespective of the time of the year, but rugged terrain was selected in summer, whereas lower elevations and sometimes westerly aspects were selected in winter. The seasonal differences largely matched the habitat use patterns of the local black-tailed deer population (Bose et al., 2018) and suggest that pumas tracked and followed the short migrations and the resulting changes in the distribution of their primary prey. This observation differed from results described from the Rocky Mountains, where pumas switched prey as a strategy to deal with ungulate migrations and changing prey availability (Elbroch et al., 2013). In California's Southern Sierra Nevada on the other hand, pumas exhibited several strategies in response to mule deer migration. Some performed a slow migration following mule deer while others 
exhibited rapid migration patterns resulting in distinct home ranges on ungulate summer and winter ranges (Pierce et al., 1999). The variation in behaviours among puma systems may reflect the different ecological drivers influencing their altitudinal migrations, or may emphasize that individual carnivores in populations exhibit different strategies to contend with varying prey availability. In our study system, $19 \%$ of the 64 collared adult female deer remained inside their home ranges yearround (Bose et al., 2017), providing some support that individual pumas may be able to successfully remain in place rather than follow elevational migrations.

Modelling outputs were somewhat supportive of our third hypothesis, that pumas would hunt alternative prey opportunistically, and that habitat selection associated with alternative prey kill sites would be similar to baseline selection. Few regression covariate estimates for alternative prey models exhibited confidence intervals that did not overlap zero, and those covariates in these models aligned with the top models of baseline selection. This suggests that pumas hunt alternative prey that are available or abundant in habitats where they hunt primary prey or opportunistically during non-foraging behaviours, but do not change their habitat selection specifically to hunt alternative prey. We wish to emphasize however that sample sizes of alternative prey kill sites were small and a larger sample might have yielded different outcomes.

Our results support the framework of most large carnivore studies, which choose to ignore non-ungulate prey when modelling hunting habitat. This approach is likely used due to the disproportionately high contribution of ungulates to the diets of large carnivores (Carbone et al., 1999), but the difficulty of locating small prey at GPS clusters of large carnivores may also be a contributing factor (Elbroch et al., 2018).

Our research suggests that pumas track black-tailed deer, their primary prey and that at least in this system, the functional responses for alternative prey exhibited by resident pumas with territories are unlikely driven by habitat selection. Further research, however, is needed to better determine why predators sometimes disproportionately select alternative prey, but kill such prey opportunistically, in other systems. Dispersing pumas disproportionately select small prey (Elbroch, Feltner \& Quigley, 2017), for example, and their prey selection may or not be influenced by habitat selection for dispersal corridors. Outcomes from such research have important implications for the management and conservation of species affected by apparent competition (Wittmer et al., 2013) particularly in complex multi-species systems where kill site habitats may also be predator specific (Apps et al., 2013).

\section{Acknowledgements}

We thank our houndsmen Blue Millsap, Cliff Wiley, Dan Tichenor and Boone Smith, as well as David Casady for help capturing pumas and numerous field technicians for help investigating kill sites. Funding was provided by the California Department of Fish and Wildlife (Agreement P0880013). Samhita Bose and Max Allen were supported by scholarships from Victoria University of Wellington.

\section{References}

Allen, M.L., Elbroch, L.M., Casady, D.S. \& Wittmer, H.U. (2015). Feeding and spatial ecology of mountain lions in the Mendocino National Forest, California. Cal. Fish Game 101, 51-65.

Apps, C.D., McLellan, B.N., Kinley, T.A., Serrouya, R., Seip, D.R. \& Wittmer, H.U. (2013). Spatial factors related to mortality and population decline of endangered mountain caribou. J. Wildl. Manage. 77, 1409-1419.

Arnold, T.W. (2010). Uninformative parameters and model selection using Akaike's Information Criterion. J. Wildl. Manage. 74, 1175-1178.

Balme, G., Hunter, L. \& Slotow, R. (2007). Feeding habitat selection by hunting leopards Panthera pardus in a woodland savanna: prey catchability versus abundance. Anim. Behav. 74, 589-598.

Barton, K. (2018). MuMIn: multi-model inference. R Package Version 1.40.4.

Bates, D., Sarkar, D., Bates, M.D. \& Matrix, L. (2007). The lme4 package. R package version 2:74.

Bose, S., Forrester, T.D., Brazeal, J.L., Sacks, B.N., Casady, D.S. \& Wittmer, H.U. (2017). Implications of fidelity and philopatry for the population structure of female black-tailed deer. Behav. Ecol. 28, 983-990.

Bose, S., Forrester, T.D., Casady, D.S. \& Wittmer, H.U. (2018). Effect of activity states on habitat selection by black-tailed deer. J. Wildl. Manage. 82, 1711-1724.

Boyce, M.S., Vernier, P.R., Nielsen, S.E. \& Schmiegelow, F.K.A. (2002). Evaluating resource selection functions. Ecol. Modell. 157, 281-300.

Burnham, K.P. \& Anderson, D.R. (2002). Model selection and multimodel inference: a practical information-theoretic approach. 2nd edn. New York: Springer.

Carbone, C., Mace, G.M., Roberts, S.C. \& Macdonald, D.W. (1999). Energetic constraints on the diet of terrestrial carnivores. Nature 402, 286-288.

Cristescu, B., Stenhouse, G.B. \& Boyce, M.S. (2015). Predicting multiple behaviors from GPS radiocollar cluster data. Behav. Ecol. 26, 452-464.

Cristescu, B., Stenhouse, G.B., Symbaluk, M., Nielsen, S.E. \& Boyce, M.S. (2016). Wildlife habitat selection on landscapes with industrial disturbance. Env. Conserv. 43, 327-336.

Dellinger, J.A., Proctor, C., Steury, T.D., Kelly, M.J. \& Vaughan, M.R. (2013). Habitat selection of a large carnivore, the red wolf, in a human-altered landscape. Biol. Conserv. 157, 324-330.

Elbroch, L.M. \& Wittmer, H.U. (2013). The effects of puma prey selection and specialization on less abundant prey in Patagonia. J. Mammal. 94, 259-268.

Elbroch, L.M., Lendrum, P.E., Newby, J., Quigley, H. \& Craighead, D. (2013). Seasonal foraging ecology of nonmigratory cougars in a system with migrating prey. PLoS ONE 8, e83375.

Elbroch, L.M., Feltner, J. \& Quigley, H. (2017). Stagedependent puma predation on dangerous prey. J. Zool. (Lond.) 302, 164-170. 
Elbroch, L.M., Lowrey, B. \& Wittmer, H.U. (2018). The importance of fieldwork over predictive modeling in quantifying predation events of carnivores marked with GPS technology. J. Mammal. 99, 223-232.

Fortin, D., Buono, P.-L., Schmitz, O.J., Courbin, N., Losier, C., St-Laurent, M.H., Drapeau, P., Heppell, S., Dussault, C., Brodeur, V. \& Mainguy, J. (2015). A spatial theory for characterizing predator-multiprey interactions in heterogeneous landscapes. Proc. R. Soc. B 282, 20150973.

Gillies, C.S., Hebblewhite, M., Nielsen, S.E., Krawchuk, M.A., Aldridge, C.L., Frair, J.L., Saher, D.J., Stevens, C.E. \& Jerde, C.L. (2006). Application of random effects to the study of resource selection by animals. J. Anim. Ecol. 75, 887-898.

Hebblewhite, M., Merrill, E.H. \& McDonald, T.L. (2005). Spatial decomposition of predation risk using resource selection functions: an example in a wolf-elk predator-prey system. Oikos 111, 101-111.

Holling, C.S. (1959). Some characteristics of simple types of predation and parasitism. Can. Entomol. 91, 385-398.

Holmes, B.R. \& Laundré, J.W. (2006). Use of open, edge and forest areas by pumas Puma concolor in winter: are pumas foraging optimally? Wildl. Biol. 12, 201-209.

Holt, R.D. (1977). Predation, apparent competition and the structure of prey communities. Theor. Popul. Biol. 12, 197-229.

Hopcraft, J.G.C., Sinclair, A.R.E. \& Packer, C. (2005). Planning for success: Serengeti lions seek prey accessibility rather than abundance. J. Anim. Ecol. 74, 559-566.

Johnson, D.H. (1980). The comparison of usage and availability measurements for evaluating resource preference. Ecology 61, $65-71$.

Johnson, H.E., Hebblewhite, M., Stephenson, T.R., German, D.W., Pierce, B.M. \& Bleich, V.C. (2013). Evaluating apparent competition in limiting the recovery of an endangered ungulate. Oecologia 171, 295-307.

Kusler, A., Elbroch, L.M., Quigley, H. \& Grigione, M. (2017). Bed site selection by a subordinate predator: an example with the cougar (Puma concolor) in the Greater Yellowstone Ecosystem. PeerJ 5, e4010.

Manly, B.F.J., McDonald, L.L., Thomas, D.L., McDonald, T.L. \& Erickson, W.P. (2002). Resource selection by animals. 2nd edn. Dordrecht: Kluwer Academic Publishers.

McLellan, B.N., Serrouya, R., Wittmer, H.U. \& Boutin, S. (2010). Predator mediated Allee effects in multi-prey systems. Ecology 91, 286-292.

Nakagawa, S. \& Schielzeth, H. (2013). A general and simple method for obtaining $R^{2}$ from generalized linear mixed-effects models. Meth. Ecol. Evol. 4, 133-142.

Nathan, R., Getz, W.M., Revilla, E., Holyoak, M., Kadmon, R., Saltz, D. \& Smouse, P.E. (2008). A movement ecology paradigm for unifying organismal movement research. Proc. Natl Acad. Sci. USA 105, 19052-19059.

Northrup, J.M., Hooten, M.B., Anderson, C.R. Jr \& Wittemyer, G. (2013). Practical guidance on characterizing availability in resource selection functions under a use-availability design. Ecology 94, 1456-1463.
Patterson, T.A., Thomas, L., Wilcox, C., Ovaskainen, O. \& Matthiopoulos, J. (2008). State-space models of individual animal movement. Trends Ecol. Evol. 23, 87-94.

Pierce, B.M., Bleich, V.C., Wehausen, J.D. \& Bowyer, R.T. (1999). Migratory patterns of mountain lions: Implications for social regulation and conservation. J. Mammal. 80, 986992.

Pitman, R.T., Swanepoel, L.H. \& Ramsay, P.M. (2012). Predictive modelling of leopard predation using contextual Global Positioning System cluster analysis. J. Zool. (Lond.) 288, 222-230.

R Development Core Team (2014). R: a language and environment for statistical computing. Vienna: R Foundation for Statistical Computing.

Ranglack, D.H. \& du Toit, J.T. (2015). Habitat selection by free-ranging bison in a mixed grazing system on public land. Range. Ecol. Manage. 68, 349-353.

Robinson, H.S., Ruth, T., Gude, J.A., Choate, D., De Simone, R., Hebblewhite, M., Kunkel, K., Matchett, M.R., Mitchell, M.S., Murphy, K. \& Williams, J. (2015). Linking resource selection and mortality modeling for population estimation of mountain lions in Montana. Ecol. Modell. 312, 11-25.

Sappington, J.M., Longshore, K.M. \& Thompson, D.B. (2007). Quantifying landscape ruggedness for animal habitat analysis: a case study using bighorn sheep in the Mojave Desert. $J$. Wildl. Manage. 71, 1419-1426.

Sawyer, H., Nielson, R.M., Lindzey, F.G., Keith, L., Powell, J.H. \& Abraham, A.A. (2007). Habitat selection of Rocky Mountain elk in a nonforested environment. J. Wildl. Manage. 71, 868-874.

Stabach, J.A., Wittemyer, G., Boone, R.B., Reid, R.S. \& Worden, J.S. (2016). Variation in habitat selection by whitebearded wildebeest across different degrees of human disturbance. Ecosphere 7, e01428.

Stephens, D.W. \& Krebs, J.R. (1986) Foraging theory. Princeton: Princeton University Press.

Stoner, D.C., Wolfe, M.L., Rieth, W.R., Bunnell, K.D., Durham, S.L. \& Stoner, L.L. (2013). De facto refugia, ecological traps and the biogeography of anthropogenic cougar mortality in Utah. Divers. Distrib. 19, 1114-1124.

Sunquist, M. \& Sunquist, F. (2002). Wild cats of the world. Chicago: University of Chicago Press.

Symonds, M.R.E. \& Moussalli, A. (2011). A brief guide to model selection, multimodel inference and model averaging in behavioural ecology using Akaike's information criterion. Behav. Ecol. Sociobiol. 65, 13-21.

Tambling, C.J., Cameron, E.Z., Du Toit, J.T. \& Getz, W.M. (2010). Methods for locating African lion kills using Global Positioning System movement data. J. Wildl. Manage. 74, 549-556.

Treves, A., Naughton-Treves, L., Harper, E.K., Mladenoff, D.J., Rose, R.A., Sickley, T.A. \& Wydeven, A.P. (2004). Predicting human-carnivore conflict: a spatial model derived from 25 years of data on wolf predation on livestock. Conserv. Biol. 18, 114-125. 
Valeix, M., Hemson, G., Loveridge, A.J., Mills, G. \& Macdonald, D.W. (2012). Behavioural adjustments of a large carnivore to access secondary prey in a human-dominated landscape. J. Appl. Ecol. 49, 73-81.

Warren, M.J., Wallin, D.O., Beausoleil, R.A. \& Warheit, K.I. (2016). Forest cover mediates genetic connectivity of northwestern cougars. Conserv. Genet. 17, 1011-1024.

Wittmer, H.U., Serrouya, R., Elbroch, L.M. \& Marshall, A.J. (2013). Conservation strategies for species affected by apparent competition. Conserv. Biol. 27, 254-260.

\section{Supporting Information}

Additional Supporting Information may be found in the online version of this article:

Fig. S1. Predicted relative probabilities for puma habitat selection in the Mendocino National Forest, California.

Table S1. Candidate models for puma baseline habitat selection in summer based on GPS location data from seven pumas in the Mendocino National Forest, California
Table S2. Candidate models for puma kill site selection of black-tailed deer in summer based on GPS cluster investigations for seven pumas in the Mendocino National Forest, California

Table S3. Candidate models for puma kill site selection of alternative prey in summer based on GPS cluster investigations for seven pumas in the Mendocino National Forest, California

Table S4. Candidate models for puma baseline habitat selection in winter based on GPS location data from seven pumas in the Mendocino National Forest, California

Table S5. Candidate models for puma kill site selection of black-tailed deer in winter based on GPS cluster investigations for seven pumas in the Mendocino National Forest, California

Table S6. Candidate models for puma kill site selection of alternative prey in winter based on GPS cluster investigations for seven pumas in the Mendocino National Forest, California

Table S7. Parameter estimates of top models $(\triangle \mathrm{AICc}<4$ and $\left.\Delta \mathrm{AICc}<\Delta \mathrm{AICc}_{\mathrm{Null}}\right)$ for puma baseline habitat selection, as well as selection of black-tailed deer and alternative prey kill sites 